\title{
ON THE DESIGN OF CLASS-J MICROWAVE POWER AMPLIFIER
}

\author{
MOHANAD ABDULHAMID ${ }^{1}$, AND KARUGU JAMES ${ }^{2}$, MUAAYED FARHAN $^{3}$ \\ ${ }^{1}$ AL-Hikma University, Iraq, ${ }^{2}$ University of Nairobi, Kenya, ${ }^{3}$ AL-Mustansiryia University, Iraq \\ E-mail: moh1hamid@yahoo.com, researchteam2@yahoo.com, farhanmoaed@yahoo.com
}

\begin{abstract}
Due to the ISM band being unlicensed for communication applications, a lot of applications have been developed in this band and a good example is WiFi IEEE $802.11 a, b, g, n$ of Bluetooth. This numeracy of applications motivated this paper. The paper is concerned with the design of a low distortion $20 \mathrm{dBm} 2.4 \mathrm{GHz}$ class-J power amplifier (PA) since PAs are indispensable in radio communications. The design is based on the AVAGO ATF-52189 transistor with a transition frequency of $6 \mathrm{GHz}$. The design is done as a hybrid circuit network realized using microstrip elements and surface mount device (SMD) capacitors. The schematic design, and simulation are carried out using Keysight's Advanced Design System version 2016.01. The simulated PA exhibited a drain efficiency of $69 \%$ and a power output of 21dBm.
\end{abstract}

Keywords: power amplifier, design, ADS

\section{INTRODUCTION}

Modern communication systems have evolved over the recent past and are still evolving largely in favor of wireless links especially at the last hop i.e. the access network. This is majorly because of the demand for mobility.

Wireless communication operates in the radio frequency (RF) range. The RF actually implies frequencies at which electromagnetic (EM) radiation is practical for communication purposes. These frequencies range from about $3 \mathrm{kHz}$ to about $300 \mathrm{GHz}$.

A very recent concept is the internet of things that arguably increases the demand for wireless communication by orders of magnitude. It is justifiably estimated that the number of smart devices connected to communication networks will far outnumber the human population in a few years' time.

This demand means that the PA designer at RF frequencies has to keep PAs performing exceptionally well especially in terms of bandwidth and efficiency. Wide bandwidth is required to support the various applications, services and capabilities from new mobile equipment. Obviously mobile equipment is battery powered and this makes power efficiency a very crucial consideration in RFPA design.

The power amplifier has a power output that necessarily far outweighs the input power driving the amplifier. Strictly speaking however, there is no such thing as power amplification and a more accurate description would be that a 'PA' is really an AC controlled DC to $\mathrm{AC}$ power converter.

PAs differ from small signal amplifiers by way of quality and quantity of signal emphasized by the designer. Small signal amplifier designers are concerned with low noise and low distortion amplification i.e. linear amplification. In short, small signal amplifier designers are obsessed with linearity. PA designers on the other hand seek to maximize power output as efficiently as possible even at the expense of linearity. The load line matching concept at the output is therefore preferred to conjugate matching. Aptly then, PA designers are obsessed with power efficiency. Recent works on PA design can be found in [1-8].

\section{DESIGN METHODOLOGY}

\subsection{Active device}

The ATF-52189 GaAs transistor was selected as the active device in the amplifier design. From the manufacturer AVAGO technologies, the datasheet was obtained from which some of the important absolute maximum ratings were extracted and are illustrated in Figure 1. All parameters in Figure 1 were adopted from AVAGO technologies [9] (the new name of AVAGO technologies is Broadcom Corporation).

\begin{tabular}{|c|c|c|c|c|}
\hline Symbol & Parameter & Units & $\begin{array}{l}\text { Absolute } \\
\text { Maximum }\end{array}$ & $\begin{array}{l}\text { Thermal Resistance } \\
\theta_{\theta t b}=52 \cdot \mathrm{c} / \mathrm{W}\end{array}$ \\
\hline$v_{\omega}$ & Dain-Scurce Vothagel] & v & 7 & \multirow{9}{*}{ 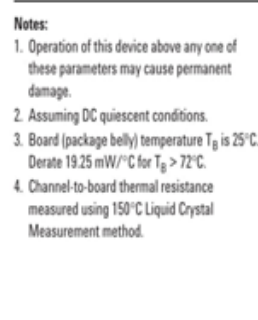 } \\
\hline$v_{w}$ & Gote-Saurce Vothoget] & $v$ & 5 to 1.0 & \\
\hline$v_{w}$ & Gate Orain Voltage $]^{[2]}$ & v & 5 to 1.0 & \\
\hline$I_{h}$ & Drain Currestex| & $\mathrm{mA}$ & 500 & \\
\hline is & Gote Current & $\mathrm{mA}$ & 46 & \\
\hline $\mathrm{P}_{\text {ts }}$ & Total Power Dissipation "II & w & 15 & \\
\hline$P_{\text {mane }}$ & Af Input Power & $88 \mathrm{~m}$ & +27 & \\
\hline$T_{\mathrm{d}}$ & Channel Temperature & ${ }^{\circ} \mathrm{c}$ & 150 & \\
\hline$T_{\text {然 }}$ & Storage Temperature & ${ }^{\circ} \mathrm{c}$ & .6510150 & \\
\hline
\end{tabular}

Figure 1. ATF-52189 absolute maximum rating

\subsection{Active device nonlinear model}

An open parasitic model of the packaged ATF52189 was obtained from the manufacturer as an ADS schematic hierarchy illustrated in Figure 2, Figure 3, and Figure 4. All parameters in these figures were adopted from AVAGO technologies [9]. 


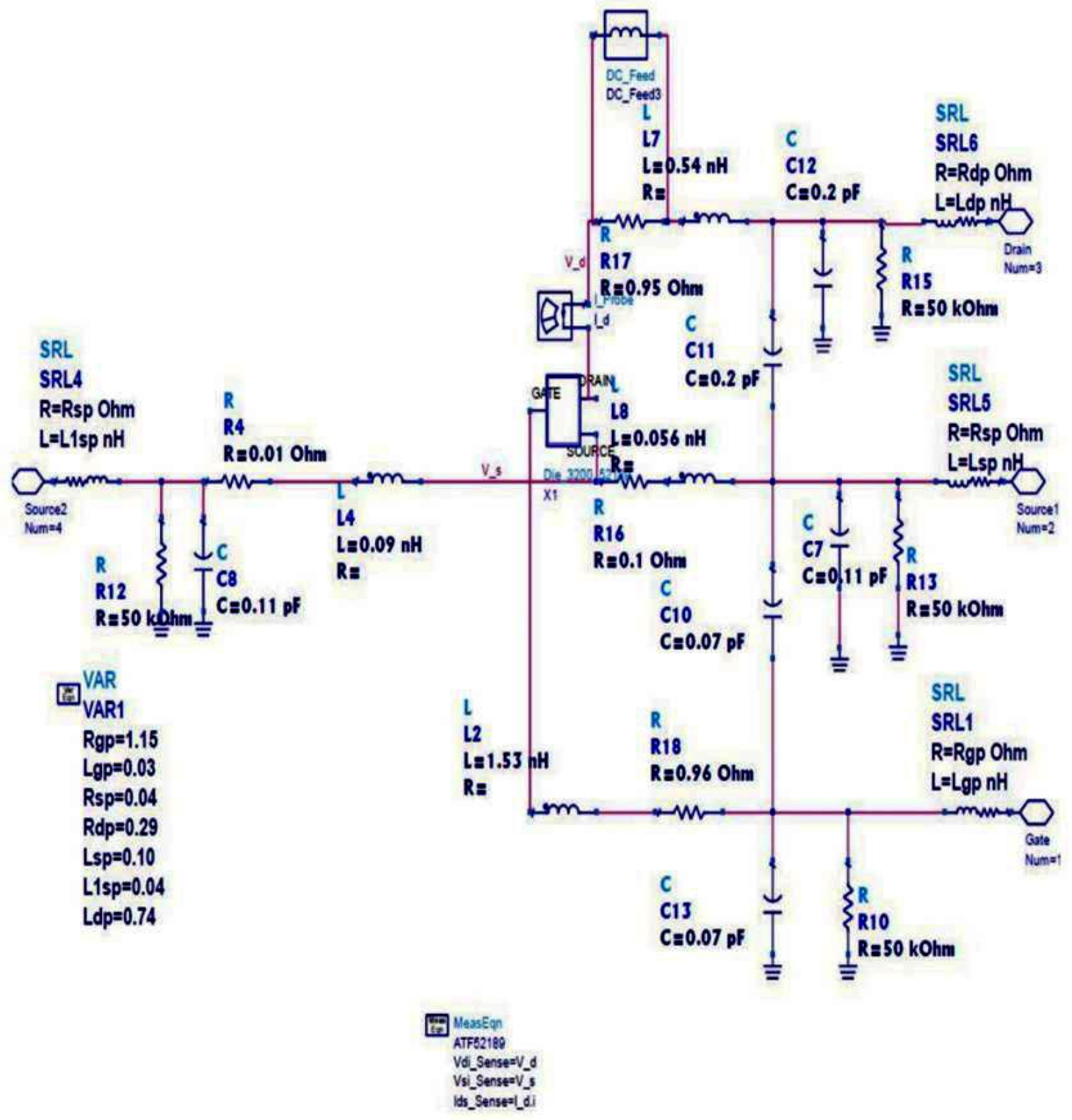

Figure 2. Extrinsic model of the ATF-52189 obtained from AVAGO Technology 


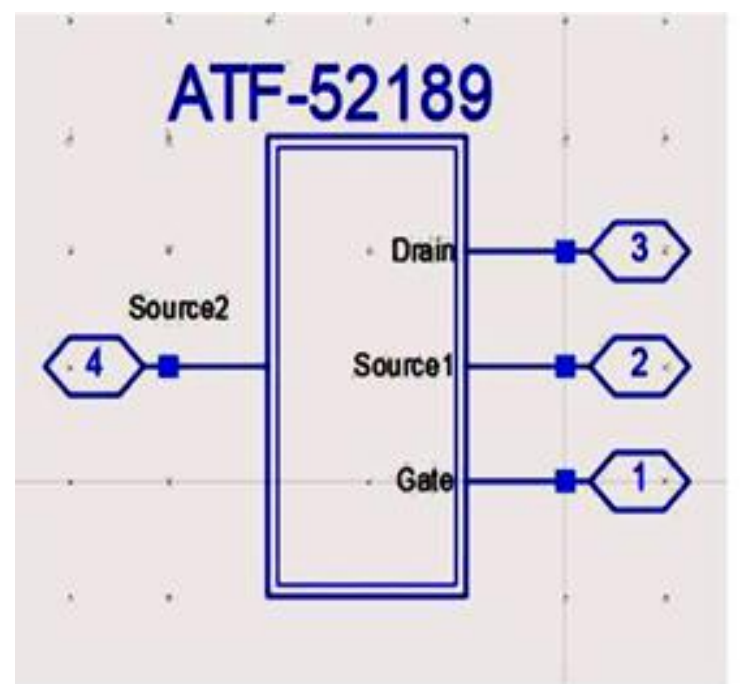

Figure 3. Schematic symbol of the ATF-52189

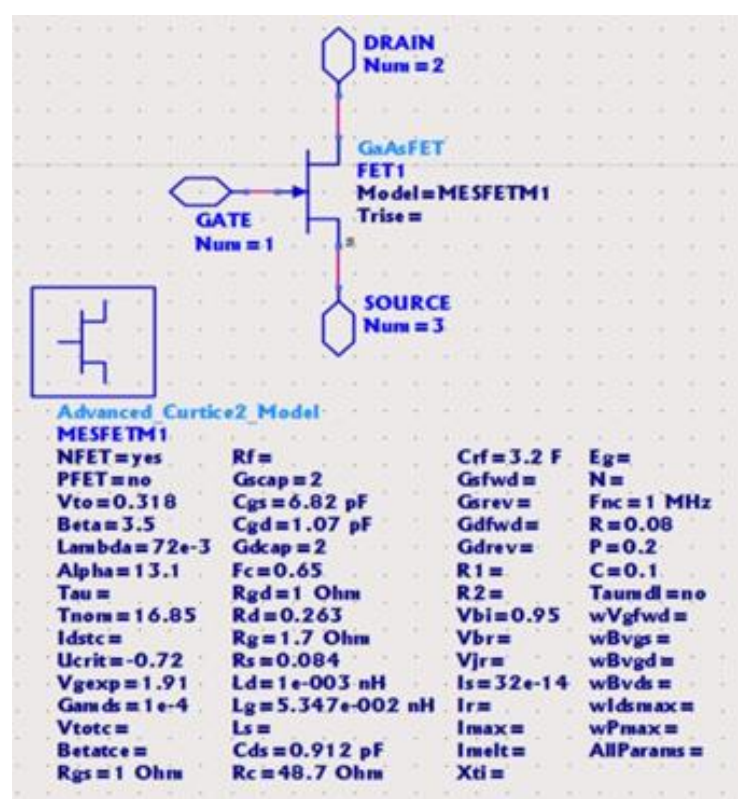

Figure 4. Intrinsic model of the ATF-52189 obtained from AVAGO technologies

\subsection{DCIV characteristics and waveform prediction from a class B load-line}

The schematic for obtaining the DCIV characteristics is illustrated in Figure 5. From the DCIV characteristics, a class B load-line was constructed from which the voltage swing and current swing were obtained. Based on these swings, class-J waveforms were predicted and plotted. The requisite fundamental and second harmonic impedances were obtained by Fourier techniques. These were the target impedances to be presented to the intrinsic drain of the device. Figure 3-5 illustrates the data display.
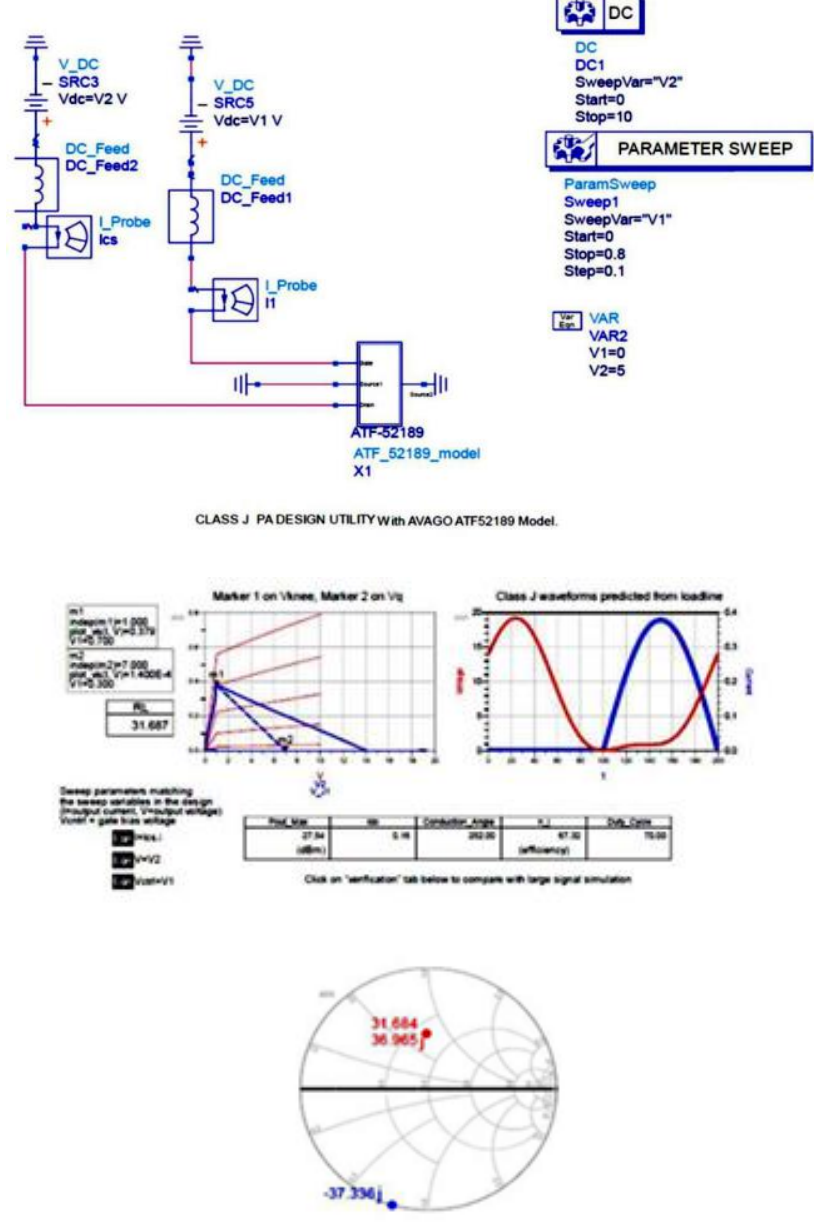

TAROET Z BASED ON LOADLNE

Figure 5. DCIV characteristics schematic capture and class J prediction

\subsection{Parasitic tune}

The impedances obtained from the load line are required at the device intrinsic node, therefore, we expect different load terminations at the extrinsic (package) node. For this reason, a parasitic tune was carried out as shown in Figure 6. Here, an equation based ideal load was presented at the output and a low power source was connected to the input of the biased device. Using harmonic balance simulation, we swept the ideal load over reasonable impedance values. The resultant intrinsic impedance was calculated from voltage and current measured at the intrinsic node.

By data display methods, the appropriate external loads for the target internal fundamental, second and third harmonic impedances were found. 


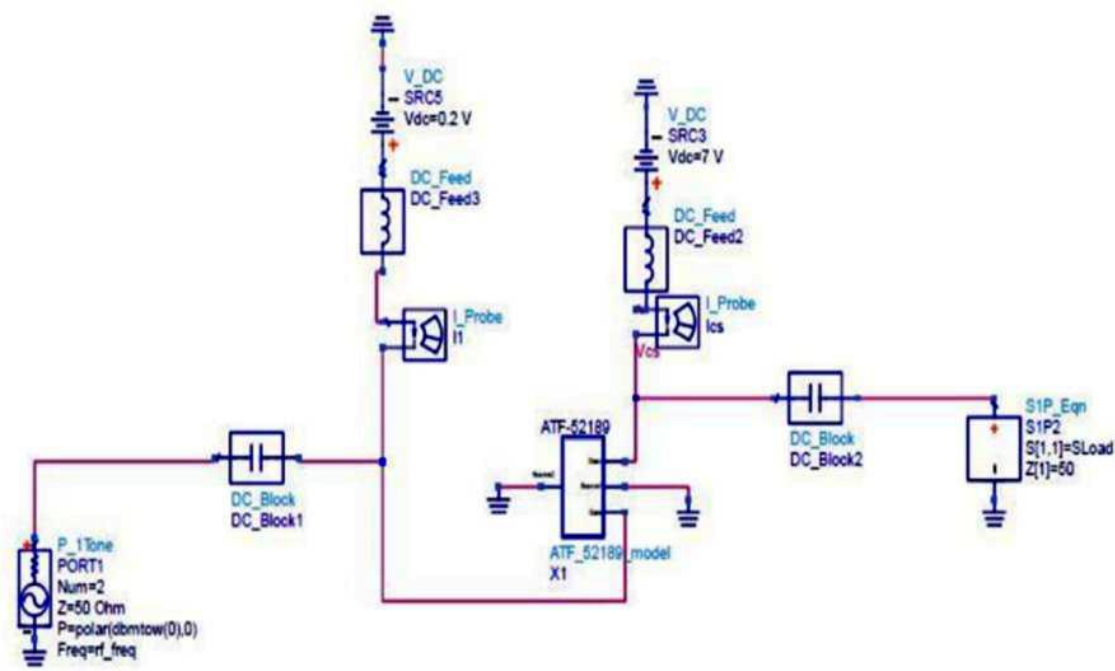

SweepRL and SweepXL and deactivate. Activate one of SweepX2, SweepX3, to sweep the impedance at one of the harmonics instead of the fundamenta:

\begin{tabular}{|c|c|c|c|}
\hline HARMONIC BALANCE & W. Parameter SWEep & W. PARAMETER SWEEP & PARAMETER SWEEP \\
\hline $\begin{array}{l}\text { HamonicBalance } \\
\text { HB1 } \\
\text { Freq(1)edt trea } \\
\text { Order }(1)=5\end{array}$ & 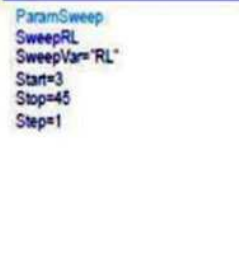 & 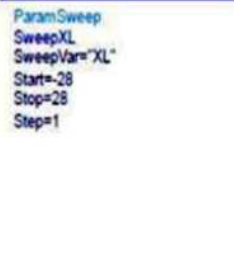 & 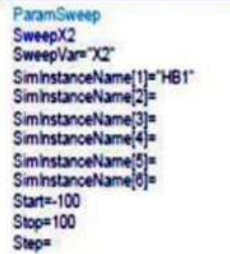 \\
\hline
\end{tabular}

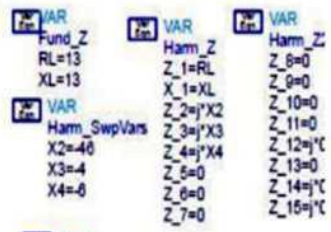

Eiv VAR IP_Calculation

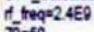

Figure 6. Parasitic tune schematic and the swept parameters

To improve the tune, the input was conjugate matched to a $50 \mathrm{ohm}$ source and the input power was adjusted so that the drain current swung over the whole dc load-line.

Figure 7, Figure 8 and Figure 9 illustrate the data display for the swept impedances at fundamental, $2^{\text {nd }}$ and $3^{\text {rd }}$ harmonics.

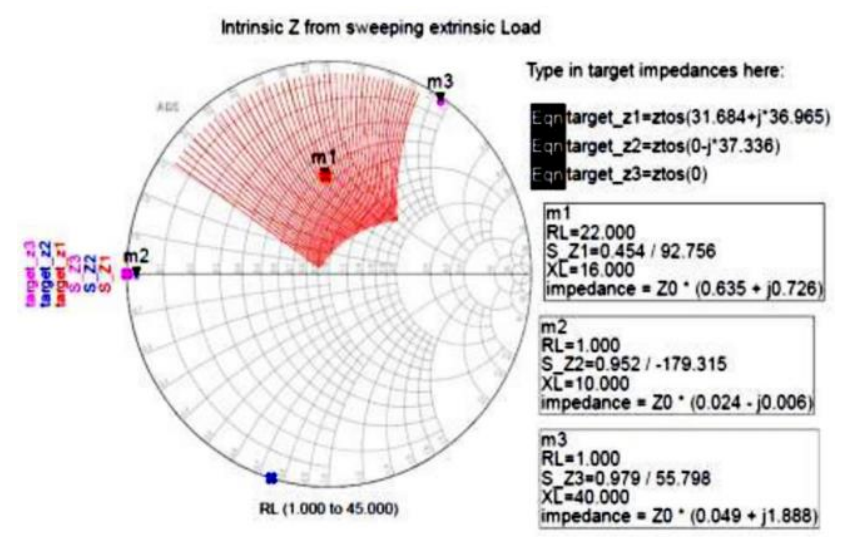

Figure 7. Fundamental load tuning

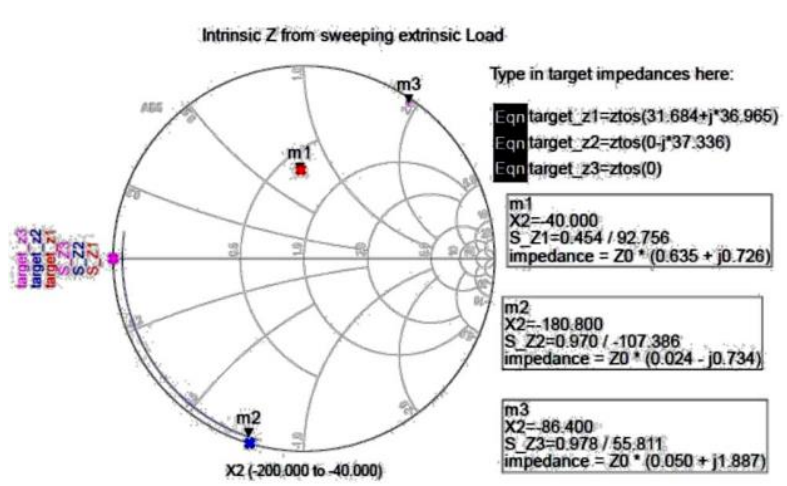

Figure 8. $2^{\text {nd }}$ harmonic tune 


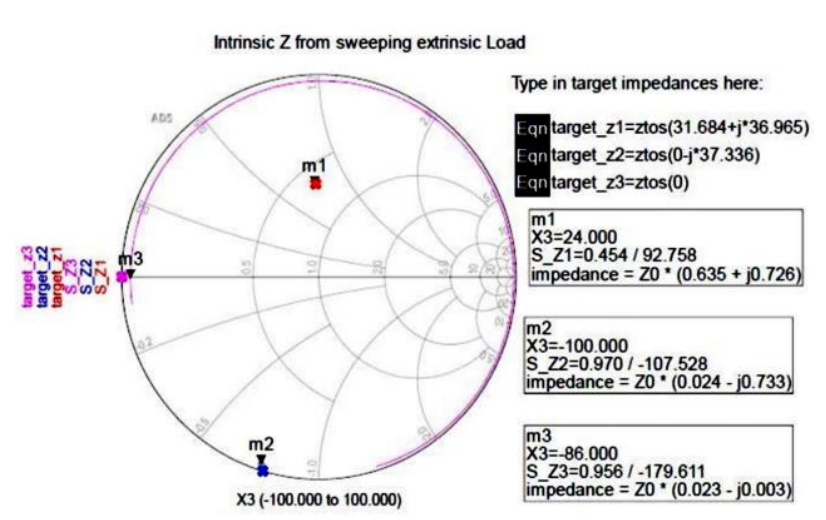

Figure 9. $3^{\text {rd }}$ harmonic tune

The circuit schematic in Figure 10 was used to determine the input impedance so that a conjugate matching network can be designed between the device and the driver
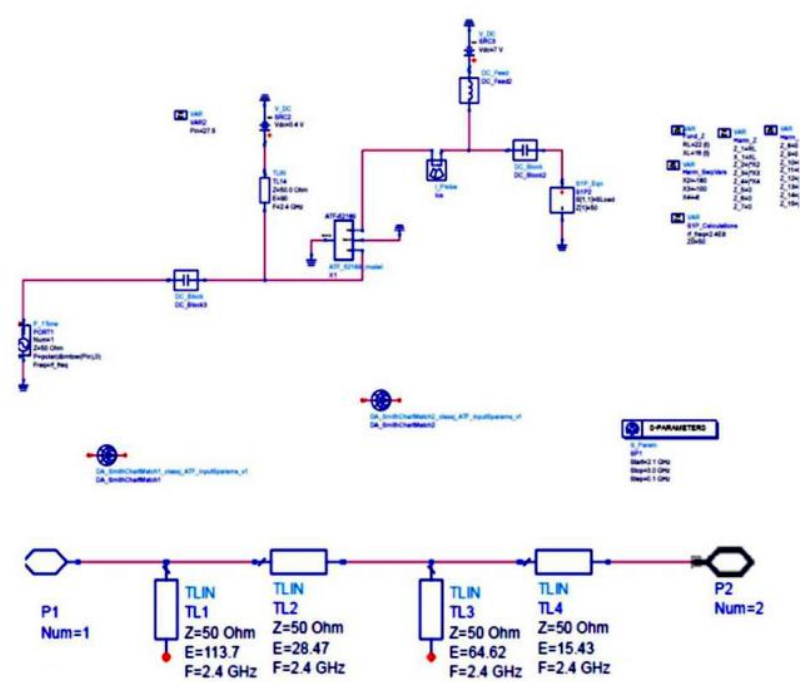

Figure 10. Input impedance measurement and matching schematic

\subsection{Output network optimization}

The external load obtained in the parasitic tune was approximated by the distributed element network illustrated in Figure 11.

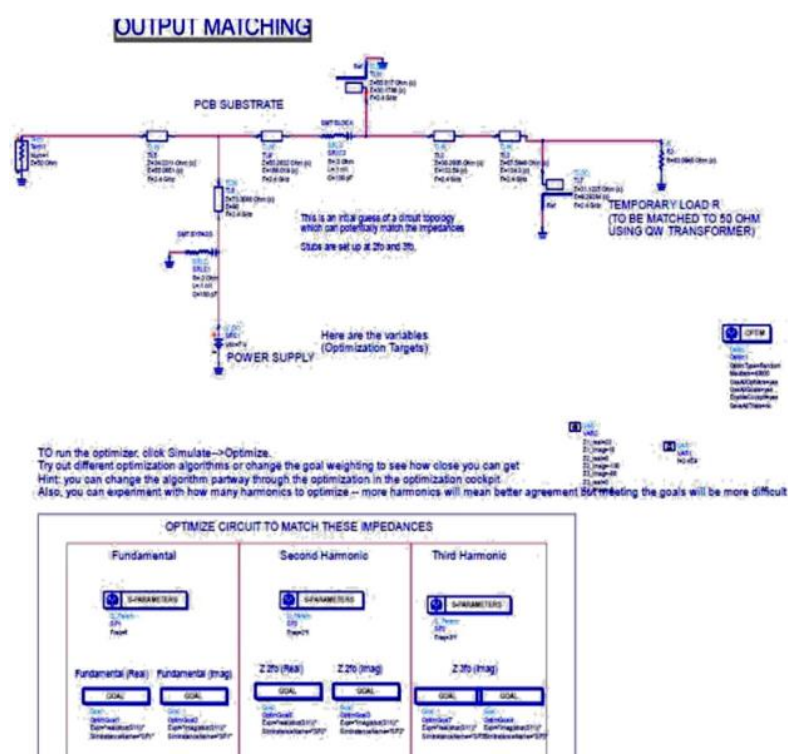

Figure 11. Output impedance optimization schematic

By defining the desired harmonic characteristics of the network as goals, the ADS optimization engine was used to fine tune each element within realizable ranges so as to closely match the desired impedances. Figure 12 captures the optimization cockpit as it runs through 40 000 iterations.

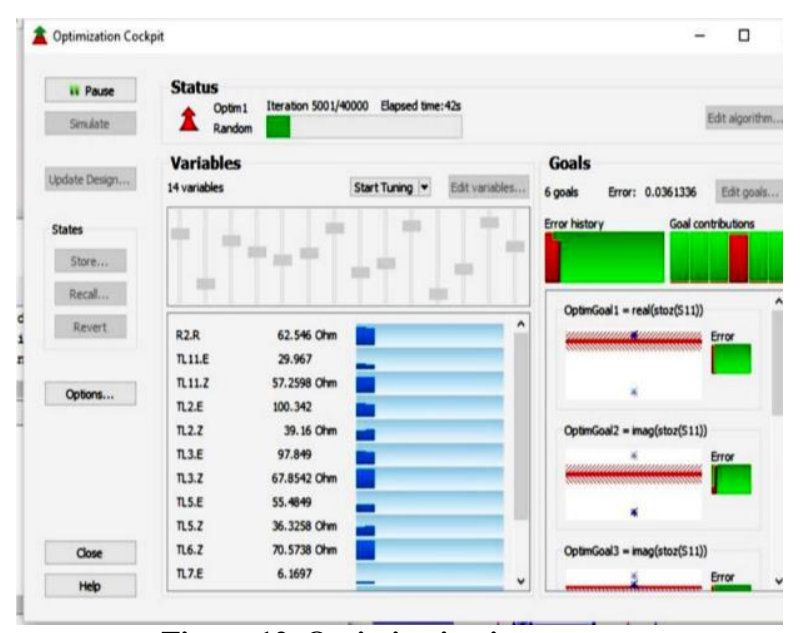

Figure 12. Optimization in progress

\subsection{Complete design simulation}

The complete schematic design shown in Figure 13 was simulated in order to compare its performance and waveforms with the load line prediction.

\subsection{Layout design}

The schematic design was converted into an FR4 substrate based layout design in readiness for fabrication. It was assumed that since the design was a simple single layer layout, EM simulation was not necessary. Figure 14 illustrates the layout design. 


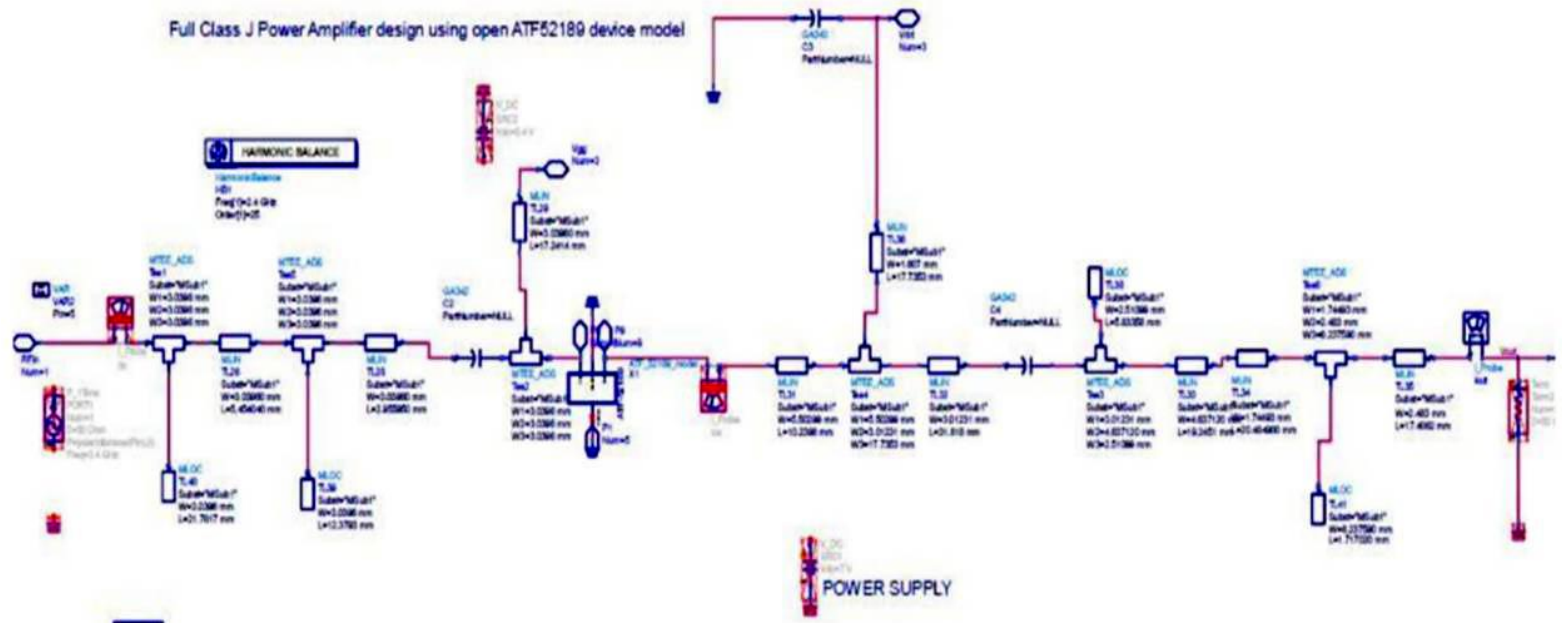

Figure 13. Complete schematic design

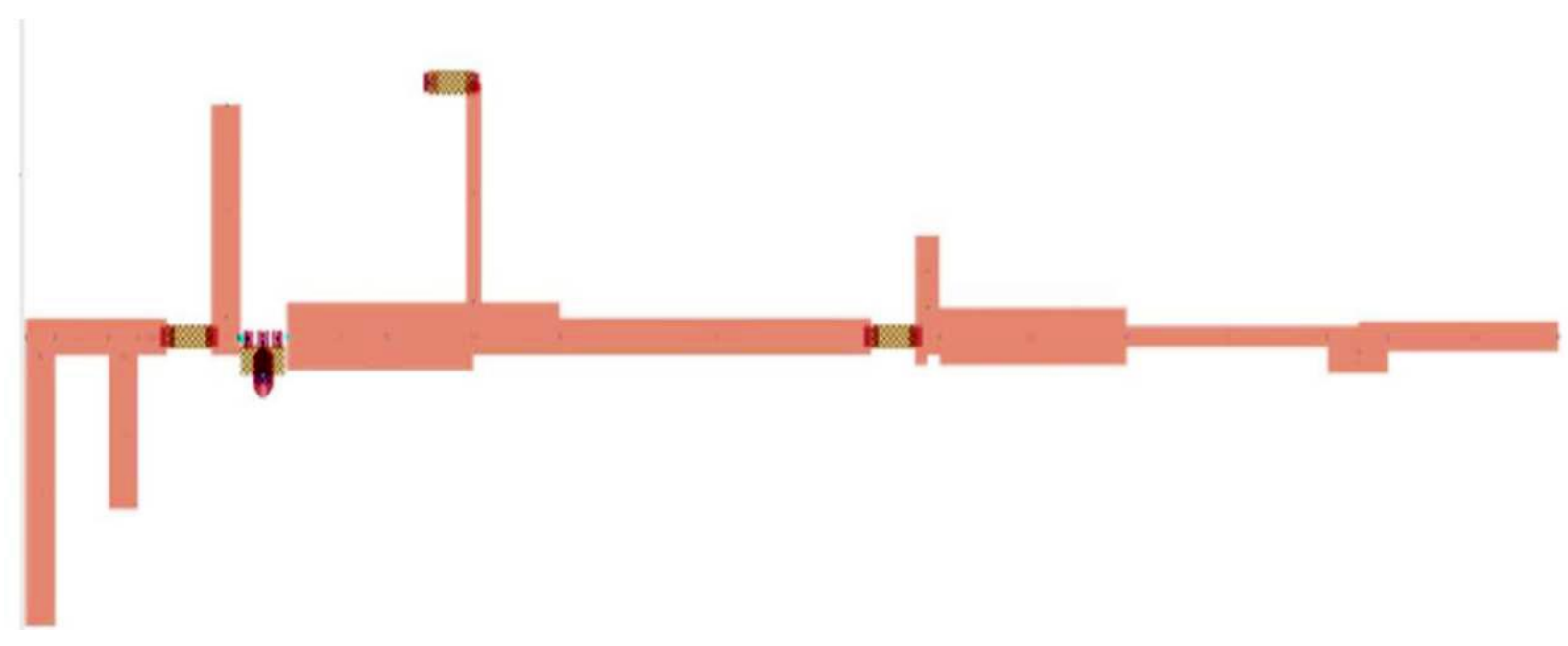

Figure 14. 2.4 GHz layout design

\section{SIMULATION RESULTS}

The simulation results are shown in Figure 15(a) and Figure 15(b). The power output and drain efficiency almost matching the predicted values from the dc loadline.

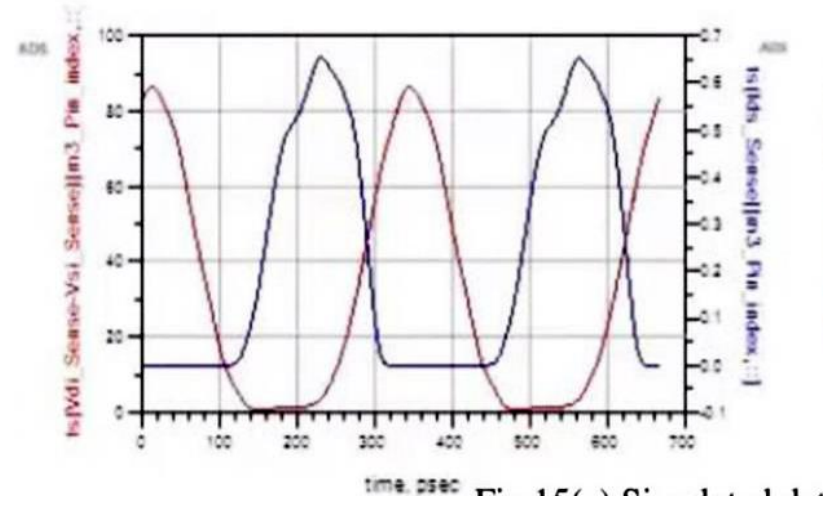

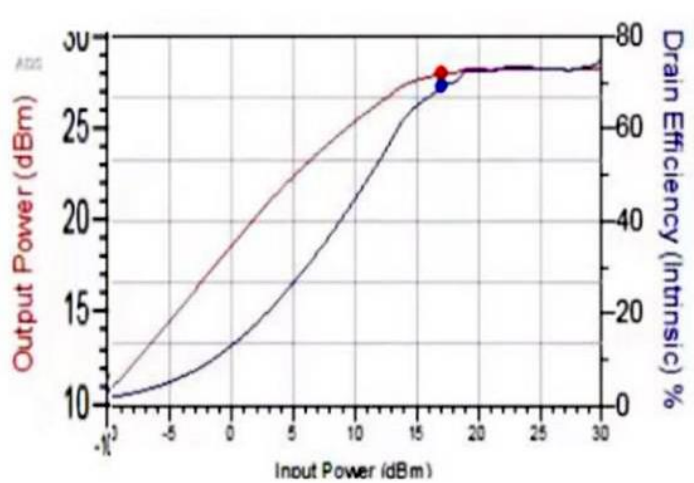

Figure 15.a. Simulated data display 


\section{CONCLUSION}

The simulated 2.4 GHz PA closely achieved the predicted class-J waveforms, power output and efficiency performance. The slight discrepancy observed was attributed to the device parasitic other than the output capacitance which was absorbed in the design. The output power designed for, $20 \mathrm{dBm}$, was slightly surpassed to yield a $21 \mathrm{dBm}$ output. The simulation results show that the PA exhibited a drain efficiency of $69 \%$ and a power output of $21 \mathrm{dBm}$ with low distortion.

\section{REFERENCES}

[1] S. Rezaei , L. Belostotski, F. Ghannouchi, P. Aflak, Integrated design of a class-J power amplifier, IEEE Transactions on Microwave Theory and Techniques, Vol.61, Issue 4, 2013.

[2] X. Zhou, L. Roy, R. Amaya, 1 W highly efficient ultrabroadband non-uniform distributed power amplifier in GaN, IEEE Microw. Wireless Compon. Lett., Vol. 23, No.4, PP. 208-210, 2013.

[3] D. Kim, An output matching technique for a GaN distributed power amplifier MMIC using tapered drain shunt capacitors, IEEE Microw. Wireless Compon. Lett., Vol. 25, No. 9, PP. 603-605, 2015.

[4] K. James, A $2.4 \mathrm{GHz}$ class-J amplifier, Graduation Project, University of Nairobi, Kenya, 2016.

[5] B. Bukvic, Simple design of a class-J amplifier with predetermined efficiency, IEEE Microwave and Wireless Components Letters, Vol.26, No. 9, 2016.

[6] M. Forouzanfar, High efficiency 8.8-9.6 GHz class$J$ power amplifier, 16th Mediterranean Microwave Symposium (MMS), 2016.

[7] A. Alizadeh, A. Medi, A broadband integrated class-J power amplifier in GaAs pHEMT technology, IEEE Trans. Microw. Theory Techn., Vol. 64, No. 6, PP. 1822-1830, 2016.

[8] A. Alizadeh, A. Medi, Distributed class-J power amplifiers, IEEE Transactions on Microwave Theory and Techniques, Vol.65 , Issue 2, 2017.

[9] http://www.broadcom.com/. 